\title{
Partitioned Nature, Privileged Knowledge: Community-based Conservation in Tanzania
}

\author{
Mara Goldman
}

\begin{abstract}
Community Based Conservation ( $\mathrm{CBC}$ ) has become the catch-all solution to the social and ecological problems plaguing traditional top-down, protectionist conservation approaches. $\mathrm{CBC}$ has been particularly popular throughout Africa as a way to gain local support for wildlife conservation measures that have previously excluded local people and their development needs. This article shows that, despite the rhetoric of devolution and participation associated with new $\mathrm{CBC}$ models, conservation planning in Tanzania remains a top-down endeavour, with communities and their specialized socio-ecological knowledge delegated to the margins. In addition to the difficulties associated with the transfer of power from state to community hands, $\mathrm{CBC}$ also poses complex challenges to the culture or institution of conservation. Using the example of the Tarangire-Manyara ecosystem, the author shows how local knowledge and the complexities of ecological processes challenge the conventional zone-based conservation models, and argues that the insights of local Maasai knowledge claims could better reflect the ecological and social goals of the new $\mathrm{CBC}$ rhetoric.
\end{abstract}

\section{INTRODUCTION}

Community Based Conservation (CBC) has become the recognized trademark of what many claim is a 'new conservation' unfolding across Africa (Hulme and Murphree, 1999; cf. Hulme and Murphree, 2001). In response to the recognized failure of top-down approaches to development and ecological limits of protectionist ('fortress') conservation, 'the community' has become the catch-all solution for effective conservation and development (McNaughton, 1989; McNeely, 1995; Western and Wright, 1994). CBC shifts the focus of conservation from nature as protected through exclusive state control, to nature as managed through inclusive, participatory, community-based endeavours. To effectively make this shift, CBC devolves natural resource management to local communities and hence is often

This article is based on research conducted in Tanzania, supported by a Scott Kloeck-Jenson International Pre-Dissertation Travel Grant. Funding for the author's dissertation research comes from a Graduate Women in Science grant, a Fulbright-Hays Doctoral Dissertation Research grant and a National Science Foundation Dissertation Improvement grant.

Development and Change 34(5): 833-862 (2003). C) Institute of Social Studies 2003. Published by Blackwell Publishing, 9600 Garsington Road, Oxford OX4 2DQ, UK and 350 Main St., Malden, MA 02148, USA 
referred to as community-based natural resource management. However, in the process, the 'community' is often reified and presented as an 'organic whole' (Agrawal, 1997). Communities, viewed as small and homogeneous units, are seen as better positioned to realize conservation goals, and as essential allies in expanding conservation beyond national park boundaries and into human-inhabited rural landscapes (Neumann, 1997).

While the hollow romanticized image of the community is itself problematic, so are the claims being made regarding the participation of communities in 'new' conservation processes (Agrawal, 1997; Barrow and Murphree, 2001; Naughton-Treves, 1999). A close look at various CBC processes across Africa suggests that while communities are now included in the politics and policies of conservation, they remain peripheral to defining the ways in which conservation is perceived and nature managed. That is, although conservation is expanding geographically, devolution and participation remain elusive or passive in nature (Agrawal and Ribot, 1999; Pimbert and Petty, 1995). ${ }^{1}$ Nature is still partitioned into protected and unprotected units through the privileged knowledge of state and non-state conservation agencies. Local communities are, in the process, viewed as tools for, or commodities of, conservation rather than as active knowing agents (Igoe and Brockington, 1999; Ribot, 1999).

In this article, I follow Jesse Ribot's call to carefully analyse 'new laws and projects masquerading as political decentralisation or community participation' by looking specifically at the new CBC agenda in Tanzania. In doing so I draw from Ribot's reading of community participation as community 'power-sharing in decision-making', which must include the 'real devolution of significant powers' (Ribot, 1999: 30). At times, I use 'community' to refer to the 'local villages' being targeted by conservationists, and at others, to imply a more abstract notion of organized Maasai societies. ${ }^{2}$ In this article, I outline how, despite the rhetoric of devolution and community participation, conservation planning in Tanzania remains a top-down endeavour; communities and the knowledge claims of local people remain

1. The geographic coverage of protected areas in Tanzania is among the highest in the world, with 27 per cent of the total land area under some form of protected status, that is, areas which prohibit human settlement ( 5 per cent national parks, 10 per cent game reserves, and 12 per cent forest reserves) (Leader-Williams, 2000). Agrawal and Ribot (1999) assert that when devolution is only administrative in effect it is not devolution at all, but rather a deconcentration of central power. Providing communities the power to administer rules without providing the power to create and refute these rules brings claims of participation, devolution and democratization into question. See Barrow and Murphree (2001) on different definitions of 'participation'.

2. Recognizing that the homogeneity assumed with the word 'community' is problematic, a more thorough analysis of the complex social relations embedded within both Maasaionly, and multi-ethnic communities is beyond the scope of this paper. See Hodgson (2001) for a nuanced look at Maasai communities. See Kiwasila and Homewood (1999) for a review of the non-pastoral diverse community interests also involved in community conservation projects in the region. 
delegated to the margins. This is shown by analysing the context of the new government policy document, planning papers, and subsequent policy, legal and academic debates regarding the building of a new CBC in Tanzania. I suggest that in addition to the difficulties associated with the transfer of power from state to community hands, $\mathrm{CBC}$ also poses complex challenges to the culture or institution of conservation. ${ }^{3}$ The intended (and at times unintended) landscapes of conservation are crafted for legibility, manageability and foreign scientific expertise, leaving little room for the inclusion of 'indigenous' or 'local' knowledge claims (Ferguson, 1994; Scott, 1998). CBC initiatives which favour the inclusion of complex local knowledge systems and uncertain, unbounded ecological processes are difficult to administer, as they do not fit into the neat managerial categories of conservation, and therefore challenge the imagined (and at times created) landscape of conservation. ${ }^{4}$

The second half of the article addresses how the challenges posed by an inclusive and participatory $\mathrm{CBC}$, as discussed in the first half, are particularly salient in the Tarangire-Manyara ecosystem, in Northern Tanzania. Here, many of the consequences or constellations of unsuccessful conservation projects further challenge the implementation of $\mathrm{CBC}$ initiatives. I discuss the need to address these challenges and engage local Maasai residents ${ }^{5}$ as active knowing agents in the conservation process, the result of which may better match the political rhetoric and social and ecological goals of CBC.

\section{THE NEW WILDLIFE POLICY IN TANZANIA: BRINGING THE COMMUNITY INTO CONSERVATION}

Unequivocally this shall be the beginning of a new chapter in wildlife conservation in Tanzania, the success and failure of which our children will live to witness (Wildlife Division, 1999: 67).

Tanzania is in the process of redefining its wildlife conservation agenda to more directly engage local communities. At the centre of this movement is the new Wildlife Conservation Policy, drafted in 1998 (see URT, 1998), hereafter referred to as 'the policy'. The policy purportedly moves beyond

3. On the transfer of power, see Agrawal (1997); Agrawal and Ribot (1999); Ribot (1995, 1999).

4. See Hulme and Murphree (2001), especially Chapter 2 (Adams and Hulme, 2001) and Chapter 3 (Barrow and Murphree, 2001) for a comprehensive and critical look at the changing conservation landscape with the emergence of Community Conservation.

5. Maasai are not the only residents in the region, which is populated by many different tribes - pastoral, agro-pastoral, and agricultural. Maasai are, however, the dominant tribe in the region, and the major focus of the 'community conservation' promotional literature of the most active wildlife NGO in the region, AWF. This article focuses on the contributions that Maasai in particular could make to conservation planning in this region due to ecological and cultural practices specific to their culture and livelihood. 
the outreach efforts of 'community-conservation' employed by the Tanzanian National Park Authority (TANAPA), by proposing real engagement through 'community-based conservation'. ${ }^{6}$ The distinction between these two approaches is expressed as that between passive versus active participation. The approach employed by the community-conservation efforts of TANAPA involves communities as passive recipients of park-outreach benefits. Active participation, on the other hand, actively incorporates communities in the ownership and management of resources (Barrow and Murphree, 2001; Barrow et al., 2000; Hulme and Murphree, 1999; Someshwar, 1993). The policy draws from the experiences of other countries (namely Botswana, Zimbabwe, and Zambia) as well as from pilot projects within Tanzania (Wildlife Division, 1999). To achieve active participation, the policy proposes the creation of a new category of land - Wildlife Management Areas (WMAs) - where local people will have 'full mandate of managing and benefiting from their conservation efforts, through community-based conservation programmes' (URT, 1998: 31, emphasis added). As such, the new policy redefines the place for 'community' within the conservation arena in Tanzania; the significance of which is expressed in the following words by the Director of Wildlife:

[This] point of departure towards accessing to the local communities the opportunity to manage wildlife on their land, in a category of protected areas to be known as 'Wildlife Management Areas' constitute[s] a major 'about turn' from the protection approach in conservation to a situation where rural communities will participate in resource planning and management, thereby benefiting economically from the resources they have lived with since time immemorial. (Wildlife Division, 1999: 68)

\section{WMAs and the Community: A Problem of Oversight ${ }^{7}$}

While WMAs are not yet an official category of land management they are more than a mere policy suggestion. With no concrete guidelines as yet to inform WMA creation or management, they are being initiated as pilot projects across the country. ${ }^{8}$ Still shrouded in ambiguity, the WMA concept has prompted much optimism for the future of community conservation in Tanzania, but it has also sparked much debate and much unease. A close reading of the policy and of subsequent discussions regarding the creation of WMA guidelines reveals the ambiguity and potential contradictions

6. TANAPA's Community Conservation Service (CCS) initiated the 'Ujirani Mwema' programme in 1991. Swahili for 'good neighbourliness', the programme works on improving relations with neighbouring villages through the provision of benefits (such as the building of schools, clinics). See Bergin (1995, 2001).

7. Latour (1999: 38) suggests that the term 'oversight' captures the two meanings of the 'domination by sight, since it means at once looking at something from above and ignoring it'.

8. Since the writing of this article the guidelines have been officially released (2003), but this has not cleared up any of the ambiguity surrounding WMAs. 
surrounding its conceptualization and plans for implementation. This suggests that the WMA concept ought to be approached with caution and an optimism perhaps tempered by a critical perspective. ${ }^{9}$

Many of the inconsistencies and shortcomings of the WMA concept were pointed out at a roundtable discussion held in Bagamoyo, Tanzania, in 1999 on the formulation of WMA guidelines. To begin with, as one of the participants acknowledged, the very definition of a Wildlife Management Area is contradictory and reflects a colonial conservation mentality (Sosovele et al., 1999: 11). A WMA, as defined in the Wildlife Policy, 'means an area declared by the Minister to be so and set aside by village government for the purpose of biological natural resource conservation' (URT, 1998: 35, emphasis added). This short definition powerfully dispossesses the very community the WMA is established to represent. As a cornerstone of community-based conservation, WMAs are defined through centralized state power for the sole purpose of conserving biodiversity. Additionally ironic is the proposed fragmentation of village lands into yet more protected areas to achieve this goal. ${ }^{10}$

The emphasis of the policy is clearly to protect wildlife and the focus remains that of supporting and, 'where necessary', enlarging the Protected Area (PA) network as the core of conservation activities towards achieving this goal (URT, 1998: 7). Communities present a new means to improve wildlife conservation - they are transformed from enemies to facilitators of the conservation process. WMAs constitute an extension of the PA system, rather than an alternative to it, as evidenced by the policy objectives for wildlife protection (see URT, 1998: 8, Section 3.2.1). Whereas the first two objectives discuss the protection and enlargement of the PA system, the third is 'to promote the conservation of wildlife and its habitats outside core areas ... by establishing WMAs'. ${ }^{11}$ The 'community' only emerges in the fifth objective, which is: 'to transfer the management of WMAs to local communities thus taking care of corridors, migration routes and bufferzones and ensure that the local communities obtain substantial tan-

9. See Igoe and Brockington (1999) and LEAT (1998) on shortcomings of the WMA concept.

10. The current re-evaluation of land rights in Tanzania reflects a similar degree of irony and confusion. The two new land acts of 1998 (the Land Act, the Village Land Act), celebrated for addressing the needs of rural Tanzanians, in fact render most Tanzanians powerless and reinstate the absolute power of the President as Trustee over all lands. See Shivji (1996a, 1996b).

11. The core wildlife protected areas in Tanzania include National Parks (NPs); Game Reserves (GRs), where human habitation and use is prohibited but hunting allowed on a permit basis; the Ngorongoro Conservation Area (NCA), with the unique status as multiple land-use area (combining habitation and use by Maasai 'pastoralists' with wildlife conservation and tourism); and Game Controlled Areas (GCA), where protection is limited to controlled hunting, with other forms of human activities (farming and grazing) permitted. 
gible benefits from wildlife conservation' (URT, 1998: 8). ${ }^{12}$ The 'community development' aspect most characteristic of CBC (Western and Wright, 1994) is presented in the policy not as a collaborative goal of conservation but as a necessary means to achieve the end result of an enlarged conservation system.

Communities appear in the conservation objectives of the policy only when they are geographically relevant to pre-existing PAs. They are not recognized as assemblages of individual decision-makers and resource-users, but are reduced to a single dimension of beneficiaries, and thereby supporters of conservation (Agrawal, 1997; Igoe and Brockington, 1999). This approach differs little from the park outreach approach that the Wildlife Division is striving to move beyond, and suggests that the 'new' conservation being proposed in Tanzania differs little from the fortress model it is posed to replace (Neumann, 1997). In fact, the discussion of WMAs cited above closely resembles the community conservation programme of TANAPA, which sought to 'keep protected areas viable by enrolling neighboring communities in their preservation' (Igoe, 2001: 2). This strategic use of communities is also reflected in the activities of conservation NGOs who work closely with government conservation agencies in Tanzania. They too are focused on signing communities on to conservation projects primarily as a means to protect the integrity of the national park system (AWF, n.d.[a], n.d. [b]). ${ }^{13}$

Rather than embracing active participation, WMAs present new ways in which communities can be acted upon. Communities are clearly not to be trusted to completely take over the management of a resource as valuable wildlife, and therefore in the end, despite the discussion of a 'transfer of management' of WMAs to local communities, 'the State will retain the overall ownership of wildlife' (URT, 1998: 6) ${ }^{14}$ As one of the many stakeholders, the community is entitled to receive 'user rights' to wildlife, provided they follow policy guidelines outlined by the state (the Wildlife Division, within the Ministry of Natural Resources and Tourism) (URT,

12. Specific benefits as noted in the policy include revenues from wildlife tourism viewing enterprises established in the area and the regulated utilization of wildlife through local hunting.

13. In a speech delivered to Hillary Clinton during her trip to Tanzania in 1997, Patrick Bergin of AWF (African Wildlife Foundation) stated, 'the uniqueness of Tanzania's wildlife stems in large part from the fact that the parks and reserves are not fenced and are part of larger ecosystems. In order to be able to maintain this situation, however, Tanzania urgently needs to work with the communities and local government authorities in areas outside of parks and reserves, and to assist these communities by giving them the legal rights, the technical knowledge and the economic incentive to maintain wildlife as one form of land use in their areas'.

14. By Tanzanian law, all wildlife in the country is under the ownership of the Director of Wildlife under the Minister of Natural Resources and Tourism. The exception is wildlife that belongs to TANAPA, by virtue of being located in national parks. 
1998). While this provision of use rights to wildlife is a radical break from past wildlife conservation policies in Tanzania and a definite positive step towards embracing the community, it falls short of constituting active participation (Sosovele et al., 1999). The allocation of use rights by the Minister (who also maintains the right to revoke such rights) reflects a top-down distribution of privileges to community members, rather than active participation. ${ }^{15}$ Even where management rights are transferred, local communities are not recognized as capable decision-makers. Rather, they are seen as 'subjects of the state', or tools of conservation that need to be 'educated, informed and guided' through standardized training, technical assistance and supervision to properly manage natural resources (Ribot, 1999: 43).

The degree to which communities are guided to effectively manage wildlife conservation in their lands is reflected in the draft guidelines proposed by the Wildlife Division for the creation and management of WMAs. The guidelines, still in draft form and still being debated within policy circles, outline a detailed, highly bureaucratic procedure for interested communities to follow. The process that communities must navigate is so bureaucratic and cumbersome that it is prohibitive rather than inviting to local communities, and far from participatory (LEAT, 1998). A reliance on 'scientific information and research results for decision making' has been noted as a 'constraint' of the proposed process (Sosovele et al., 1999). In order for a community to have a WMA established, the village council (locally elected government unit) must first acquire an official title for all village land, a procedure which not only overshadows customary mechanisms regarding land tenure but often in the process radically transforms the fluid nature of customary tenure negotiations in place within villages (Leach et al., 1999; LEAT, 1998; Neumann, 1997). ${ }^{16}$ The village must then prove, through systematic scientific data collection, the existence of significant wildlife resources (of economic value and ecological viability) within the area proposed for WMA status (URT, 1998, 2000). An official land-use plan then needs to be prepared and approved by the District Council. The land-use plan must include a designated area set aside exclusively as a WMA within the communal village lands (Wildlife Division, 1999). Zoning is also conducted for other land-use practices within the village such as seasonal grazing, cultivation, forests, social services, and reserved land (Njoroge,

15. On revocation, see URT (2000). See Ribot (1999: 48), for a critique of a similar situation regarding use right privileges in participatory forestry projects in Sahelian West Africa.

16. See Shivji (1996a) on the problems associated with village titling in Tanzania as envisioned in the Land Act (1998) and Village Land Act (1998). The most destructive outcome of village titling is the ease with which village land is then leased to non-village members and effectively put out of customary use by villagers. Within the Manyara-Tarangire Ecosystem the dividing up of land has been particularly prevalent in Simanjiro District (Igoe and Brockington, 1999; Amy Cooke, pers. comm.). See Galaty (1992) for examples of land-subdivision among Maasai in Kenya. 
2000). The delineation of 'exclusive zones' is also suggested to accommodate the resource needs of 'traditional communities' such as hunter-gatherers (Dorobo, Hadzabe) and pastoralists (Maasai), residing within a WMA (Severre, 2000). Official land-use maps are presently being created with the guidance and technical expertise of outside NGOs (AWF, Instituto Oikos) and District government officers, to prepare villages for WMA creation. It should be noted that these activities are strategically occurring in areas where conservation agencies would like to protect important wildlife corridors and grazing dispersal areas, such as the Tarangire-Manyara Ecosystem, as discussed below.

Once official land-use plans and scientific inventories are in place, they must be approved by district and state governing bodies. An 'Authorized Association' must then be formed and approved within the village to effectively manage the WMA (URT, 2000). ${ }^{17}$ Upon the Minister's review and approval, a WMA is declared within the said village. The village level Authorized Association, is not, however, its sole management authority, but one of a long list of partners forming a joint management team for the WMA. Other partners include village, district and national governing bodies and wildlife authorities (from TANAPA). Additionally, to 'ensure the success of community-based conservation', the village (through the Authorized Association) is required to utilize officially trained village game scouts in administering their limited powers (LEAT, 1998; URT, 1998:14; 2000). These game scouts must be trained at official government institutions where they are taught 'basic knowledge about methods of monitoring and sustainable utilization of natural resources' (Sekamaganga, n.d.; Wildlife Division, 1999).

The guidelines outlined for the creation of WMAs suggests that local communities are only capable of 'active participation' in the conservation process after receiving extensive official training and, even then, only in partnership with other key (and presumably more informed) players. In fact, in a recent speech at Mweka College of African Wildlife Management, the Director of Wildlife clearly spelled out his belief in the inability of local communities to effectively manage a WMA. He explained that in order to avoid the 'legacy of failure of community imposed development organisations' characteristic of Tanzania, 'it is necessary to put in place guidelines and regulations pertaining to the establishment and management of WMAs, which must involve many partners'. These partners are to provide respective communities with 'the necessary skills, money, and investment opportu-

17. District Council approval is needed first, then the approval of regional authorities and finally the Minister of Wildlife and Natural Resources, through the Director of Wildlife. The creation of Authorized Authorities also involves a long process of guidance and approval, where a village first establishes a $\mathrm{CBO}$, whose constitution and structure needs to be approved by the District Council. The CBO then needs to apply to be upgraded into an Authorized Association (Wildlife Division, 2000). 
nities' to manage a WMA (Severre, 2000: 15, emphasis added). However, if one flips the coin to view these partnerships from the side of the state, local communities surface as necessary partners, to the enlargement of wildlife protected areas, or as Director Severe states in his speech, as 'defined operational cushions to core protected areas, thereby increasing the total area under effective conservation' (ibid.: 14, emphasis added). The Director further clarifies the importance of WMAs in protecting those habitats defined as wildlife corridors and dispersal areas, which he claims currently have no legal form of protection. To assure that 'community-based' conservation in WMAs runs smoothly, the government will not only be involved in training community members, but will remain an active partner, and will for 'sometime... partially have its hands off but its eyes on, to ensure that sustainable conservation and development is attained' (ibid.: 21).

\section{THE UNMANAGEABLE UNCERTAINTY OF THE LOCAL}

In reviewing the social and legal aspects of the new CBC plans for Tanzania, a team of lawyers and scholars made the following suggestion: 'Since the [wildlife policy] encourages the use of indigenous knowledge in the conservation of natural resources, the NRC [Natural Resource Council] should ensure that any training builds on and develops indigenous knowledge systems and does not merely replicate the modern game scout training which government is so fond of' (LEAT, 1998: 17).

Indeed the policy does suggest that 'enhancing the use of indigenous knowledge in the conservation and management of natural resources' should be a strategy for recognizing the 'intrinsic value of wildlife to rural communities' (URT, 1998: 17-18). At the workshop on the formulation of WMAs, Dr Songorwa, the CBC Officer for the Wildlife Division, stressed the use of indigenous knowledge as one the four rationales of a CBC approach to conservation (Wildlife Division, 1999: 78). Nonetheless, the policy's objectives and procedures for WMA formation (some identified above) reflect a lack of attention to indigenous knowledge. The words of the Director of Wildlife exemplify the general lack of trust in the capacity of the village to manage natural resources without close supervision and official scientific training and guidance.

Why is it that the new defining legislation to bring the community into conservation in Tanzania effectively circumscribes the community's rights of participation, keeping the community peripheral to the process? And how is it that 'indigenous knowledge' is favourably mentioned in the document and within policy circles, while at the same time it is effectively ignored in practice? In addition to the difficulties involved in the relinquishing of power by the state, the implementation of $\mathrm{CBC}$ requires a radical 
transformation of the culture and institution of conservation. On the one hand, this transformation requires a simple shift in viewing local people as partners rather than enemies of conservation (Barrow et al., 2000; Kiss, 1990). This shift, while occurring at the policy level, is more difficult to put into practice on the ground. Conservation policies in Africa have been, and continue to be, enforced through paramilitary forces charged with protecting nature from human (usually local) disturbances (Peluso, 1993) ${ }^{18}$ In some places, $\mathrm{CBC}$ is no more than a changing of the guards, as local village game scouts are trained in fortress-based conservation procedures such as the use of firearms, and the maintenance of paramilitary anti-poaching patrols (Sekamaganga, nd); it is therefore questionable if a shift is being made at all.

However, another more subtle, but perhaps more challenging, shift is one towards accepting the value and legitimacy of local, indigenous knowledge claims. Here, the neat administrative boundaries and scientific categories utilized by conservationists face the challenge of incorporating (or acquiescing to) the uncertain and complex patterns of local ecological and social processes. This challenge, while difficult, is necessary to truly integrate communities into $\mathrm{CBC}$ processes, and to more closely address the ecological processes of concern to conservationists.

Alternatively referred to as traditional, practical, or indigenous, local knowledge claims are now recognized by many scholars as valuable for conservation, in being more responsive to temporal and spatial heterogeneity and intimately connected with an understanding of historical ecological processes at the local scale (Brush and Stabinsky, 1996; Fairhead and Leach, 1996; Zimmerer, 2000). Scott (1998: 324), for instance, suggests that '[t]he power of practical knowledge depends on an exceptionally close and astute observation of the environment'. One could easily see why such local insight might be readily embraced by conservationists eager to understand the ecological details of the local landscape (Berkes et al., 2000). This would, however, require those in power to acknowledge that such knowledge exists, that it has value, and that it can be incorporated into a scientific conservation planning (Hobart, 1993). The current CBC policy of Tanzania makes none of these assumptions and rather sees local people as needing education, 'technical advice' and 'training' to effectively manage and especially to conserve natural resources (URT, 1998: 15). At the base of the education campaign is the village game scout training mentioned above,

18. Military-trained game scouts have trouble redefining their relationship with communities, and members of these communities are often confused and distrustful of such attempts. The irony of the situation was aptly expressed by a Maasai informant regarding the 'good neighbourliness' community conservation project of TANAPA in border communities of Tarangire National Park: "Good neighbours" they say, good neighbours with your enemies. Why? They beat us, take money illegally [fines], now they want to be friends' (from interview with author, August 2000). 
which includes the teaching of Western scientific techniques for the identification of plant and animal species, range management, and water conservation. There is no room in the syllabus for the incorporation of the local knowledge of the trainees. In fact, there are presently no attempts to ascertain the knowledge claims of local villagers, despite recognition by some conservation agencies that such knowledge exists and would probably be valuable to their efforts (Kahurananga, pers. comm.).

Several explanations could be provided for this disparity between the praise for indigenous knowledge in policy circles, and its simultaneous disregard on the ground - explanations which stem from the constraints of the conservationist culture and institutions. Despite growing ecological and social research suggesting the contrary, the conventional wisdom associating rural, 'traditional' people as backward and ignorant is difficult to dislodge (Brockington and Homewood, 1999; Hobart, 1993). Where local knowledge is recognized as valuable, it does not readily lend itself to the precise measurement, exact calculation, or rigorous logic called for by conservation agencies (Scott, 1998: 320). Institutions such as the World Bank and USAID, leaders in the development industry and now actively involved in conservation, have in general denigrated local knowledge and proposed Western scientific alternatives (Ferguson, 1994; Hobart, 1993; Scott, 1998). The African Wildlife Foundation (AWF), possibly the most active conservation NGO in Tanzania, was founded as an American elite conservation organization to train and educate Africans to ensure the continuation of wildlife conservation after independence (Bonner, 1993). Pedagogy and the replacement of traditional mechanisms and local knowledge with Western scientific tools are just as fundamental to the institution of conservation as to that of development. Pastoralists in particular, whose resource management strategies involve seasonal (transhumance) migrations in response to climatic variability, pose a challenge to precise zonebased land-use planning.

The need to present indigenous knowledge as other and opposed to scientific knowledge maintains the power of science as an antidote to local backwardness in both development and conservation activities (Ferguson, 1994). Despite (and perhaps because of) its present glorification in the literature, indigenous knowledge remains the other or alternative in opposition to Western scientific expertise. In the context of this polarization, we should be cautious, as Agrawal (1995) argues, in focusing too much attention on the differences between the indigenous versus Western scientific knowledge claims. However, it is nonetheless important to acknowledge certain differences between indigenous and/or local and Western scientific knowledge claims, as played out on the ground - through processes of negotiation and conflict - in specific conservation initiatives. Here, the locally situated and 'practical' nature of much local knowledge is often silenced by the official and presumably universal conservation science 
discourse, as upheld by more powerful actors of state agencies and international conservation NGOs. ${ }^{19}$

In arguing for the importance of 'local' or practical knowledge, Scott uses the term metis to depict a knowledge that is different yet not so distant from, and continually interacting with Western scientific knowledge. As he suggests: 'Metis, with the premium it places on practical knowledge, experience, and stochastic reasoning, is of course not merely the now-superseded precursor of scientific knowledge. It is a mode of reasoning most appropriate to complex material and social tasks where the uncertainties are so daunting that we must trust our (experienced) intuition and feel our way' (Scott, 1998: 327).

In addition to experience and intuition, the power of the 'practised eye', metis is also about experimentation, precise skills, and complex knowledge. ${ }^{20}$ While finding Scott's term metis valuable, I prefer the term 'local' knowledge for two reasons. First, to avoid caricaturing local knowledge as inherently a different type of knowledge from scientific knowledge - the former always practical and the latter always discursive; and second, to underscore the spatially situated aspect of the knowledge held and utilized by community members regarding their local environment. While much indigenous knowledge arguably transcends the local, the particular expertise it imparts regarding local ecology is specifically relevant for conservation planning.

Conservationists working with dynamic ecological processes such as those characteristic of semi-arid environments, may well benefit from the insights and practical experience of local knowledge (Niamir-Fuller, 1999; Scoones, 1995; Zimmerer, 2000, 1994; cf. Behnke et al., 1993). However, both the dynamic nature of ecological systems and the fluid, negotiated nature of much local knowledge and practice pose direct challenges to state-sponsored conservation activities, which rely on the creation and maintenance of legible and manageable landscapes. There is little room in these landscape creations to incorporate the uncertainty and complexity of natural and social systems, let alone the negotiated nature of local knowledge claims.

19. While state agencies, NGOs and academic scientists often differ in opinion and approaches to conservation policy, they are all working within the framework of Western scientific traditions of wildlife ecology, conservation biology, landscape ecology and resource management. In fact, there is a transparent association between the thoughts expressed in many scientific articles regarding wildlife conservation in Tanzania and the desires of state and conservation NGOs regarding conservation policies: see Mwalyosi (1991); Prins (1987).

20. As such, one could argue that rather than a separate type of knowledge from what is considered 'scientific', metis is a part of all knowledge production processes, including scientific. That is, personal, practical knowledge is a part of all knowledge. For example, the ability of a ecologist to recognize and identify different ecological patterns is the result of personal skill, the practised eye, and expertise combined with scientific training. The work of Michael Polanyi (1969) is particularly valuable in uncovering the practical and personal nature of all knowledge, including scientific. 
The process of land-use planning that is currently unfolding as part of the $\mathrm{CBC}$ initiatives in Tanzania is a case in point. Although communities are being brought into the planning process, their land-use techniques and forms of social and ecological organization need to conform to recognized land-use categories and approved land-use planning practices. The rigid boundaries and neat land-use zones make the landscape much more legible and manageable (for conservation officials) than the 'buzzing complexity and plasticity' of customary tenure negotiations (Scott, 1998). In the process, however, much of the intricate institutional frameworks co-ordinating local resource management systems is lost (Leach et al., 1999; Turner, 1999b). The codification of land ownership and use contradicts more flexible 'customary' laws often applied to land-tenure negotiations (Leach et al., 1999; Neumann, 1997). The rigidity in time and space of the land-use planning, ignores, and as a result disrupts, flexible land-use management techniques.

The consequences of denying the legitimacy of local knowledge claims goes beyond the political and social ramifications felt by the communities themselves. The landscapes created in the process are much less responsive to the local ecological processes to which local knowledge has adapted. This is particularly true in the semi-arid environments, where people and animals migrate in response to changes in local ecology. Semi-arid savanna ecosystems are characterized by extreme spatial and temporal heterogeneity, where seasonal and annual variations in rainfall interact with topographic and edaphic variation, affecting vegetation quality and quantity across the landscape (Behnke et al., 1993; Hopkins, 1983; Little, 1996; McNaughton and Georgiadis, 1986; Menaut, 1983; Turner, 1998). In such ecosystems local land-use practices reflect intimate understandings of complex ecological processes at local and regional scales (Coughenour, 1991; Scoones, 1995; Turner, 1999a; Walker, 1993). Attempts to transform local land-use systems that do not consider this complexity and diversity will likely fail at the very least, and, at worst, have detrimental effects on both the social and ecological systems in question. The continued promotion of such Westernscientific management strategies as zone-based planning, despite recurrent failures, can be attributed in many ways to the culture of conservation I have been referring to throughout this section. Such practices are a vital part of conservation and development planning, universalized for use everywhere. We will now turn to an area that is receiving much attention from conservationists, the Tarangire-Manyara Ecosystem, to address these issues more specifically.

\section{CBC IN A NATURAL-SOCIAL LANDSCAPE OF THE TARANGIRE- MANYARA ECOSYSTEM}

Nature, like taste, is subjective. In the broadest sense, nature means the realm of animals and plants. But does it also mean, as many Western cultures would have it, the absence of human activity?

(Western, 1989: 158). 
The existence of wildlife in Africa cannot be detached from culture. Wildlife is not found everywhere in Africa

(Parkipuny, 1991).

Haraway (1989: 15) suggests that the theoretical separation and compartmentalization of that which 'we have come to know historically as nature and culture' is itself problematic (see also Braun and Castree, 1998; Cronon, 1996). The practical application of this artificial dichotomy onto existing landscapes proves overly simplistic and unrealistic. The current debate about the ecological limitations of national parks stems from the difficulties of segregating out pieces of the landscape that are often intricately interconnected (Schonewald-Cox and Bayless, 1986; Western and Gichohi, 1993). The limitations of neat demarcation are well exemplified by the Tarangire-Manyara Ecosystem of northern Tanzania.

The ecological and social boundaries defining the ecosystem, also referred to as the Tarangire-Manyara or Maasai Steppe Heartland, remain deeply ambiguous (see Figure 1). ${ }^{21}$ Central to all definitions of the boundaries is an explicit attempt to define the ecological and social systems integral to the functioning of the Lake Manyara and Tarangire National parks. The two parks, however, comprise only 28,000 ha of an estimated total of 370,000 ha for the ecosystem, which also consists of 263 villages across five districts, where Maasai constitute roughly 80 per cent of the population (AWF n.d.[a], n.d.[b]). Variations in vegetation quality across the system occur as a function of topography, soil quality, rainfall, and fire and grazing history. This variation effectively determines the resource use patterns of wildlife and domestic livestock. Every wet season thousands of wild animals migrate from Tarangire National Park (TNP) east, across several Maasai villages, to graze alongside Maasai cattle in the nutrient-rich Simanjiro Plains, while others migrate between TNP and Lake Manyara National Park, across Maasai occupied lands in the Kwakuchinja corridor (Kahurananga and Silkiluwasha, 1997; Lamprey, 1964; TMCP, 2002; Voeten, 1999). ${ }^{22}$ The national parks, far from maintaining enclosed ecosystems, have been drawn around only dry season watering and grazing areas. For more than six months of the year, most wildlife is found outside of the national parks, in community/village lands.

This movement of wildlife between protected 'patches' and Maasai grazing lands highlights the importance of wildlife conservation outside park boundaries and in the human-inhabited landscape (Western, 1989). It also reflects the

21. The region is alternatively referred to as the Manyara-Tarangire Complex (LEAT, 1998), the Tarangire-Manyara Heartland (AWF n.d.[a], n.d.[b]), the Maasai Steppe Heartland (AWF web site: http://awf.org/heartlands); Masai [sic] Ecocomplex (Mwalyosi, 1991), and the Masai [sic] Ecosystem (Prins, 1987).

22. The Simanjiro Plains are in 'Maasailand', lands inhabited and 'claimed' by Maasai. In Swahili, such areas are referred to as 'Maasaini', literally the Maasai place. 
Figure 1. Map of the Maasai Ecosystem. Approximate boundary (shaded) encompassing Lake Manyara and Tarangire National Park as well as the Kwakuchinja area and the Simanjiro Plains

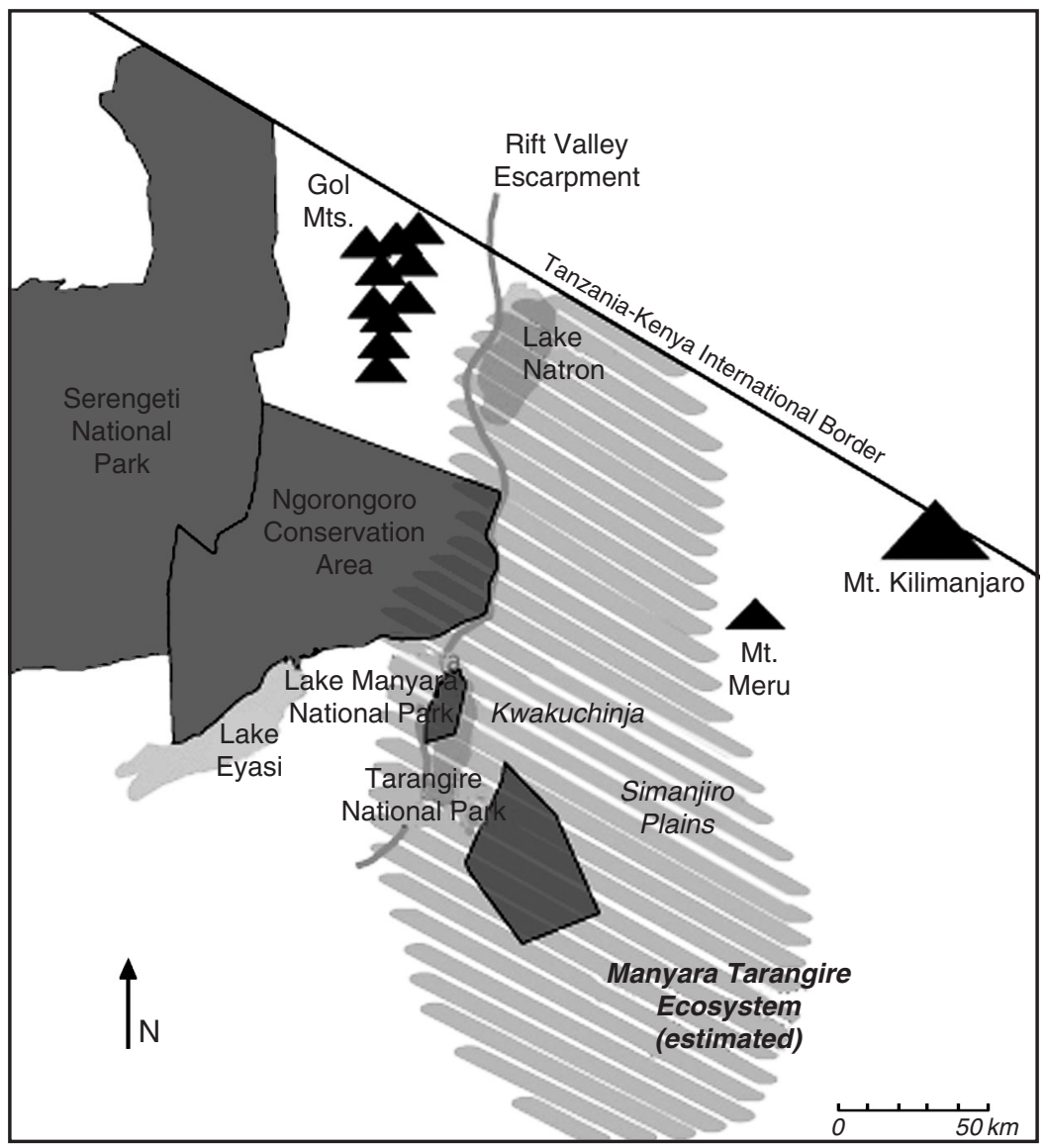

(Based on Prins, 1987)

relative historical ecological compatibility of Maasai pastoralism with wildlife conservation (Arhem, 1985; Brockington and Homewood, 1999; Collet, 1987; Deihl, 1985; Homewood and Rodgers, 1991; Jacobs, 1975; Knowles and Collet, 1989; Lindsay, 1987; Parkipuny and Berger, 1993). CBC initiatives are therefore expanding throughout the region, to integrate wildlife conservation with the socio-economic needs of the Maasai and achieve 'large-landscape' level conservation (AWF, n.d.[a]). The CBC initiatives are being led by AWF in partnership with TANAPA, and the Wildlife Division, and are based on the formation of WMAs throughout the area. 
The critiques presented in the previous section are of great significance here for two main reasons. First, the migratory behaviour of the wildlife makes fluid land-management regimes necessary, yet land partitioning, land-use planning, and zoning are still being employed. Second, the conservation of wildlife is dependent on local Maasai, who share the land. Yet, while the image of Maasai in conservation circles has shifted radically from that of degrading, destructive pastoralists to the new custodians of wildlife, Maasai knowledge claims are still ignored or considered inadequate for conservation purposes. ${ }^{23}$ Here, 'the Maasai' have replaced 'the community' in the new conservation discourse; reified and romanticized, yet simultaneously marginalized. In this section I outline some of problems that these contradictions produce in achieving landscape-level conservation in this region. I first problematize the political and ecological fragmentation of the landscape that is occurring as a result of conservation initiatives and then turn to the role that Maasai could play in the $\mathrm{CBC}$ process as active, knowledgeable participants.

\section{A Divided Landscape}

In drawing lines between and within natural and social systems, conservation activities have in effect bifurcated the continuous landscape of the Tarangire-Manyara Ecosystem that they are promoting. Now, realizing the continuous nature of many ecological processes (particularly wildlife migrations) across the landscape, conservation endeavours aim to blur the very lines they have drawn. Here, the (un)intended consequences of conservation projects can be seen as the creation of politically and ecologically fragmented landscapes. That is, even where conservation projects have failed to maintain the ecological integrity of boundaries between nature (national parks) and society (neighbouring communities) as planned, a political boundary was constructed and remains powerful. ${ }^{24}$ The boundaries' power lies in politically dividing communities from nature conservation and in transforming local land-use patterns to adhere to this division. As they strive to 'unite' conservation and development to achieve landscapelevel conservation, conservationists need to mend these divisions - politically and ecologically. Ironically, in the Maasai Ecosystem, this task is being

23. Interestingly, this shift has not been complete and since both views are romanticized exaggerations and not based on any direct understanding of Maasai land-use practices, they can co-exist. That is, Maasai grazing practices can be demonized as unproductive and primitive, while the image of the 'indigenous Maasai' living in harmony with nature is called on when needed by wildlife conservation agencies and safari companies.

24. Examples of the ecological failure of boundary drawing are reflected in continual movement of people and resources across the boundary: the annual migrations of wildlife beyond park boundaries and the utilization ('poaching') of resources inside the park boundaries by local people. 
approached through the creation of new ecological divisions to partition the landscape: WMAs.

AWF claims that 35 per cent of the Tarangire-Manyara Ecosystem will be 'brought under conservation management - both community and protected - within the next couple years'. They plan to utilize CBC and work in partnership with Maasai communities to achieve this goal. Maasai pastoralism is viewed as more compatible with wildlife conservation than are other land-use activities such as cultivation. Conservationists, therefore, promote the expansion of CBC (and of course, WMAs) in 'pastoral' communities as a step towards uniting the landscape and its various conservation and development needs. ${ }^{25}$ Maasai, however, view the situation differently. The new WMA movement appears to them to be a step towards the further fragmentation of their landscape. They see the political structure and bureaucratic requirements of WMAs (as described above), as a means of putting their community lands under the control of district authorities. ${ }^{26}$ The creation of WMAs is therefore viewed as the continuation of a process of segregation rather than a mending of past divisions and conflicts. The following observation from the LEAT (1998: 20) report clearly illustrates this point:

What is now the MTC [Manyara/Tarangire National Parks Complex] was part of the Maasailand pastoral ecosystem, until when it was separated to become exclusive lands for wildlife [sic]... This development greatly reshaped and reoriented Maasai's notions of spatial organization in their entire habitat. What hitherto constituted a broad Maasai cosmological mosaic was replaced by a fragmented habitat characterized by dual landscapes separated by unequal power relations, originating from the utilisation and management needs differential of the now split ecosystem.

Maasai pastoralism as a form of land-use in the area relies on access to various patches of grazing resources across the larger ecosystem throughout the year. The seasonal movements of Maasai cattle are quite similar to the migratory movement of wildlife. ${ }^{27}$ Historically, Maasai have maintained semi-permanent homesteads in areas with year-round water and grazing and migrated to wet-season pastures where mineral-rich grazing is available during the rains (November or December to May). Organized systems of

25. This approach ignores the importance of cultivation to Maasai. To many if not all Maasai in the Tarangire-Manyara ecosystem, small-scale cultivation has become a vital component of their livelihood practices. Again, the romantic notion of Maasai pastoralists is not grounded in an understanding of the complex reality of land-use in the area. See Lama (1998), McCabe et al. (1992) and O'Malley (2000) for a look at how small-scale cultivation in Maasai communities can co-exist with pastoralism and wildlife conservation.

26. Anonymous interviews with author, 2003.

27. The author's current research is looking at the co-use of grazing resources by Maasai livestock and wildlife in the Kwakuchinja corridor region; also see Lama (1998); Voeten (1999); Voeten and Prins (1999). On Ngorongoro see Arhem (1985) and Homewood and Rodgers (1991). 
land-use management exist to co-ordinate migrations, grazing and watering patterns. ${ }^{28}$ Today, most Maasai in the Tarangire-Manyara Ecosystem maintain permanent homesteads. Grazing is still organized, however, to take advantage of seasonally available water and pasture, and livestock are still moved over long distances when necessary, by Masai ilmurran (young men of the 'warrior' age-group, of approximately 15-30 years of age). However, as the above citation by LEAT illustrates, the creation of conservation areas throughout Maasailand has disrupted their land-use system, forcing Maasai to re-structure their movements accordingly. The creation of Tarangire National Park removed important grazing and water resources, including early wet-season grazing areas, permanent water sources (the Tarangire River and Silalo Swamp) and drought refuge sites, from use by Maasai pastoralists in the region. ${ }^{29}$ This caused distortions in the utilization of resources throughout the Maasai Ecosystem (LEAT, 1998). Maasai in the region, while maintaining a predominately pastoral livelihood, are finding it more difficult to subsist on pastoralism alone. Thus, they are supplementing their activities with subsistence and small-scale commercial agriculture (Amy Cooke, pers. comm.; Lama, 1998; LEAT, 1998; Muir, 1994). The loss of land to conservation areas is of course not the sole reason for these changes. The increase in large-scale agriculture also poses a competing threat to pastoralism. ${ }^{30}$

Increased large-scale cultivation not only poses a threat to pastoralism, but is also viewed as a huge impediment to wildlife conservation. However, although conservationists are embracing pastoralism as a more wildlifecompatible form of land-use, they are not addressing the needs of pastoralists. These needs include, among other things, access to grazing and water resources, and freedom of movement, not dissimilar to the needs of migrating wildlife. Ironically, however, they also include the freedom to cultivate on a small-scale basis, to produce food for themselves and their families.

Conservationists realize the importance of the needs of migrating wildlife. Research in Tarangire National Park has verified the ecology behind the migrations, asserting that, 'if animals were forced to stay year-round in their dry season range, current population numbers of migratory herds would decline' (Voeten et al., nd: 96). As a consequence, AWF and others are working to protect migratory routes, by preventing the spread of cultivation and supporting pastoralism with wildlife. While the complete creation of

28. This simplified overview does not do justice to the complex range management regime employed by the Maasai pastoralists. For a more detailed review see Homewood and Rodgers (1991) and Potkanski (1994) for the Maasai in Ngorongoro, and Igoe and Brockington (1999) for Maasai in Simanjro and Mkomazi.

29. Anonymous interviews with Maasai elders and senior warriors in Simanjiro and Monduli by author (2000; 2003); also see Igoe (2001); Igoe and Brockington (1999).

30. While many Maasai in the region are now practising small-scale cultivation, the large farms are mostly owned by Waarusha residents or other people from outside the area. 
new strictly protected areas in the region may not politically be an option, the establishment of WMAs is. ${ }^{31}$ As we saw above, establishing WMAs requires creating land-use plans, including an area exclusively for wildlife conservation. Participatory Land-Use Maps (PLUMS) are being created throughout the area to locate different land-use activities within discrete categories that are then digitized into Geographic Information Systems (GIS) maps. ${ }^{32}$ While land-use maps can be helpful, strict zone-based planning contradicts the fluid nature of wildlife movements as well as those of pastoral herds, and therefore risks further disrupting both Maasai pastoral practices and wildlife movements. ${ }^{33}$ Here the desire to create a legible system of management based on Western understood notions of tenure and management could have effects quite contrary to initial conservation goals.

In addition to the ecological and socio-economic 'segregation effects' discussed above, the creation of national parks in the Maasai Ecosystem has also produced cultural transformations within Maasai communities. ${ }^{34}$ As the above citation from LEAT illustrates, the reshaping of the landscape into protected and unprotected areas effectively transformed the way Maasai in the area frame their relationship with nature, particularly wildlife. As a by-product of fortress-style conservation, communities that once accepted wildlife in their midst now view the animals as intruders and see conservation as a threat. Again, I draw from LEAT's analysis to illustrate this point:

[L]and alienation among these communities has left scars far beyond what can be explained just in economic terms. The alienation has also recast Maasai political as well as cultural perceptions on those who were/are involved in managing lands alienated for wildlife purposes. This has invariably led to Maasai redrawing their traditional relationship with the animals of the wild and the institutions charged with managing them. (LEAT, 1998: 22)

These changes ultimately threaten the acceptance that Maasai have historically exhibited towards wildlife. Without romanticizing Maasai as 'custodians of wildlife', it should nonetheless be recognized that Maasai communities have historically been more tolerant of wildlife in their midst then many of their neighbouring tribes. As Parkipuny states (1989: 8), 'It is not a mere accident of history that many of the most spectacular wildlife protection areas in East Africa were carved out in territories previously part

31. The proposal for the creation of a new multiple-use protected area, similar to NCA (see fn 6), was vehemently opposed by resident Maasai in Simanjiro.

32. Participatory land-use maps were done for three villages in the study area by the OIKOsheaded Tarangire Manyara Conservation Project (TMCP, 2002). Mapping efforts are also being co-ordinated by District Land offices (Simanjiro and Monduli).

33. See Hodgson and Schroeder (2002) on the underlying complexities associated with various community-based mapping projects occurring in this region.

34. Western and Gichohi (1993) argue that the very creation of national parks often produces a suite of 'segregation effects' - social and ecological impacts of segregating otherwise joined ecological and social processes. 
of Maasailand'. Much of Maasai tolerance towards wildlife is related to their predominantly pastoral way of life. Wildlife was seen as a creation of God with equal rights to grazing lands as Maasai cattle, as evidenced in the names often used for smaller plains animals: inkinejie Nkai ('the goats of God') and inkishu e Nkai ('the cattle of God') (Fr. Filiberto, Apostle of the Nomads, pers. comm; see also Berger, 1993). Historically Maasai did not eat wild game meat and looked down on those tribes that did. Today, Maasai make a clear distinction between 'what they see as their animals and what are the animals of the government' (LEAT, 1998: 22). Wildlife is now the animal of the government. ${ }^{35}$ And today it is not uncommon to find Maasai who eat wild game if given the opportunity. ${ }^{36}$

This same division has occurred with regard to conservation. Maasai often refer to themselves as good 'caretakers' of their environment and see themselves as a part of the ecosystem. For instance, the Maasai of the Ngorongoro Conservation Area refer to the Serengeti/Ngorongoro highlands as Ramat, meaning 'a healthy habitat for people and animals' (Taylor and Johansson, 1996). However, the word conservation, or its Swahili equivalent kuhifadhi, is thought to reflect the men in the buildings of the conservation area authority (Goldman, 1998). Similarly, at a CBC workshop in the Manyara-Tarangire Heartland area, conservation was interpreted by Maasai participants as the 'preservation of wild animals only' and for the sole benefit of TANAPA (Njoroge, 2000: 4). The leaders of the meeting (members of a Maasai NGO, Inyuat e Maa) acknowledged that, 'It was only after serious discussion that participants appreciated that conservation includes more than just wild animals [and] as a community, they are already involved in conservation, and therefore there was nothing new' (ibid.).

A new conservation area in the Tarangire Manyara Ecosystem, the Manyara Ranch, incorporates pastoral herding by two neighbouring villages, ranching, and wildlife conservation. ${ }^{37}$ Maasai resented the area being called a 'conservation area' as conservation is viewed as 'government owned', wildlife-only, and non-Maasai. The Maasai name, Ramat was proposed by Maasai villagers as an appropriate name for the area, meaning 'pastoralists and the environment; the people, the cattle, and the wildlife'. ${ }^{38}$

35. While driving, I have frequently been warned by Maasai friends not to hit the 'government's chickens' (quail and guinea fowl).

36. Maasai do not hunt game for food but many will eat game meat when available. As one man explained to me, 'it's development; we have learned that its not bad to eat game meat'. Ironically this man 'learned' to eat game meat while working as a labourer building a lodge in Tarangire National Park.

37. The Manyara Ranch is owned by the Tanzanian Land Conservation Trust and is still in the early stages of development. My current research looks at how Maasai knowledge (through Maasai participation) could be incorporated into management of the Manyara Ranch.

38. Interviews of Maasai villagers and members of the Manyara Ranch steering committee (2003). 
Conservationists are now presenting Maasai as natural allies of wildlife in their attempts to expand CBC throughout the Maasai Ecosystem. However, over the past several decades, Maasai have come to view conservation, and often by association, wildlife, as enemies. These feelings reflect a history of land alienation through conservation, repeated most recently with the eviction of Maasai from the Mkomazi Game Reserve in Northern Tanzania (Brockington, 2001; Brockington and Homewood, 1999; Neumann, 1995; Rogers et al., 1999). The effects of this eviction continue to be felt throughout the Maasai Ecosystem, as evicted herders renegotiate for grazing rights and Maasai land-use strategies spatially readjust to accommodate their needs (Igoe and Brockington, 1999). For many Maasai, conservation is synonymous with the loss of grazing land (and the ability to farm). Thus, they remain distrustful of any 'new' conservation initiatives. Continued $\mathrm{CBC}$ discussions focusing on the strict demarcation of land into protected and unprotected areas, and pushing Maasai resource management practices and ecological knowledge to the margins, will only reinforce these fears.

\section{The Missing Piece: The Local Knowledge of Maasai Pastoralists}

[A]ny formula that excludes or suppresses the experience, knowledge, and adaptability of metis risks incoherence and failure; learning to speak coherent sentences involves far more than merely learning the rules of grammar. (Scott, 1998: 319)

Memut elukunya nabo eng'eno

One head does not encompass all knowledge. ${ }^{39}$

An AWF project director acknowledged his perception of the final outcome of Maasai livelihood practices, as the maintenance of large wildlife herds in Maasai-occupied lands. He also acknowledged having limited information on why this was the case. This is the common story - anecdotal accounts about Maasai being the 'custodians of wildlife' abound, yet few attempts have been made to understand the practical relationship Maasai have with wildlife and the resulting specialized Maasai knowledge. While the comments of the AWF officer acknowledge the value of examining and incorporating Maasai indigenous knowledge into conservation initiatives, there is no space within the current CBC structure to do so. AWF is tied in many ways by the guidelines dictated by the Wildlife Division (as spelled out above) regarding WMA formation. Additionally, their own institutional history and that of conservation in East Africa constrains them further. Nonetheless, AWF does claim to have not only 'found community' (Agrawal, 1997), but also the promise of harmony and indigenous knowledge embodied within the notion of a Maasai community, as proclaimed in AWF funding proposals for $\mathrm{CBC}$ initiatives. Why then

39. Maasai saying, quoted in Rigby (1992: 1). 
is every $\mathrm{CBC}$ project in the Maasai Ecosystem based on education and training? Why not ask how the belief of a harmonious relationship between Maasai and wildlife came to exist; what the real relationship looks like; and what Maasai know about wildlife? Teaching of 'official' wildlife-conservation policies to Maasai without first asking these questions not only contradicts the espoused rhetoric of the CBC project, but risks transforming local practical knowledge and land-use patterns in adverse ways.

The game scout training, as mentioned above, is popular in Maasai villages, but while the young warriors (illmurran) participate in the training, they often do so because they get paid to, and because they get to see fellow illmurran from distant villages; they usually pay little attention to the actual training. ${ }^{40}$ Illmurran have their own mechanisms of training, including direct teachings by sponsors or instructors (olpiron - elders who belong to the alternate age-set above them), meetings and peer gatherings among themselves (Orpul - meat eating camps in the woods where junior warriors learn from their seniors), daily activities of herding and taking cattle for water, and seasonal moving of cattle to wet-season pastures or in search of water during droughts (Kipury, 1983). As a result, illmurran receive an education that includes detailed ecological understanding of their surrounding environment. The system of learning during murranhood is explained in the following words of a Maasai olmurrani:

Our education is acquired out there on the grazing grounds. We spend our days, months and years exploring the brown plains which extend to Siringet [Serengeti]. Instead of passing intemat [tests] about things that are foreign, we test our knowledge of our environment by actually getting into thorny bushes, the home of many wild animals. Instead of playing empira onkejek [football], we chase after colorful birds and hunt small animals in the open woodlands. Instead of dansi oo nkeresa [English dance] we have our enkipaata and emowua olkiteng [boy's ceremonial dances which mark the formation of new age-sets]. (cited in Berger, 1993: 24)

This quotation provides much insight into the ways in which Maasai obtain detailed knowledge of their surroundings, a process that continues beyond the period of murranhood, and is different for men and women. It suggests that knowledge is obtained through daily interactions with local ecology, both plants and wildlife. For men, this interaction revolves around herding. According to Lama, 'herders' livestock management depends to a great degree on wildlife movements, for reasons of predation, competition for water and pasture, and disease/parasite interaction, they are therefore very aware of seasonal wildlife movements' (Lama, 1998: 62-3). My own discussions with Maasai confirmed this statement and I would add that in addition to avoidance mechanisms, Maasai herders closely observe the movements of wildlife to locate good grazing.

40. Interview with anonymous Maasai senior warrior in Simanjiro (July 2000). 
Two Maasai elder warriors, in a meeting with me, indicated in Swahili and Maa the specific places from which wildlife leave Tarangire Park, the routes used to reach specified locations in the Simanjiro plains and for how long they stay. The confidence with which the two men drew the map, and pointed to similar locations on a printed map was revealing. Additionally, the locations named where wildlife exit the park closely match those named by Kahurananga and Silkiluwasha (1997: 181). Maasai place names are one example of the detailed knowledge Maasai possess regarding local ecology and wildlife land use. Maasai place names reflect differences in vegetation composition, vegetation structure, water sources, animal presence (such as where the wildebeest stay, the field of the lion, the place of elands), as well as historical social ecology. For instance, Elang'ata Olowuarak - the river crossing of the lion - refers to a very specific location that is used by lions, and other wildlife as well, to cross the river that cuts through a grassland in Oltukai Village in the Kwakuchinja corridor region (Goldman, 2002). Much research has revealed the level of detailed local-plant knowledge many Maasai employ for the purpose of human and veterinary medicine production (Kipury, 1983; Minja, 1999; Ole-Lengisugi, 1994; Ole-Lengisugi and Mziray, 1996). This same attention has not been accorded to knowledge regarding wildlife.

While not suggesting the production of an inventory of Maasai ecological knowledge, the above discussion begins to illustrate the degree to which Maasai produce and utilize detailed knowledge about their environment. Also implied in this discussion is a recognition of Maasai knowledge as inseparable from Maasai resource management practices, land-use techniques, tenurial arrangements and institutional structures. This suggests that, first, the official game scout training and land-use planning procedures required for WMA creation may not be entirely appropriate; and second, that Maasai have much more to offer $\mathrm{CBC}$ as active knowledgeable participants, than is currently recognized.

While this section has suggested the wealth of information regarding wildlife and local ecology within Maasai communities, I should stress that this 'information' should not be viewed as easily codified and extracted, but rather as knowledge utilized, and continually transformed, by active agents. I refer back to Scott's (1998) metis to denote a locally-situated group of knowledges stemming from a combination of formal-cultural learning mechanisms, practical skill attainment, experimental techniques, and social dialogue. This type of knowledge is not easily codified or translated into the concrete management regimes upheld by conservation agencies in the area. However, I would argue that the ability to combine certain aspects of Maasai practical knowledge with certain scientific understandings should not be dismissed. While remaining cautious to not force each 'type' of knowledge to fit into the mold of the other, the differences between the scientific and the indigenous should not be exaggerated (Agrawal, 1995); for such an exaggeration would deny their necessary engagement. 


\section{CONCLUDING COMMENTS}

In this article I have attempted to uncover the many contradictions inherent within the current $\mathrm{CBC}$ movement in Tanzania: those between rhetoric and practice, as well as those between the desired goals of conservation and the suggested means to achieve them. While NGOs, donor agencies, and government authorities may claim to have 'found community', this paper has revealed the limited impact this finding is really having on conservation policy. It seems these agencies need to continue to grapple with the question of how to reshape their own institutions and agendas to really fit communities - with their diverse needs, knowledge, and complex social and ecological structures - into conservation. In the Maasai ecosystem, this would suggest a shift in focus from the 'village' unit of community, to Maasai socially and ecologically defined boundaries and their accompanying governing institutions, from statutory to customary-tenure structure, and from exclusive-scientific management to a dialogue of reconciliation between Western-scientific and local-Maasai knowledge claims. It would in effect, require an acceptance of a Maasai geographical understanding of the landscape, from notions of boundary drawing, to ecological knowledge and resource-management processes

These suggestions require definite shifts in the existing power structure regarding conservation in Tanzania. Agrawal (1997: vii) argues, 'communitybased conservation is unavoidably about a shift of power'. However, as this article implies, Tanzania's new wildlife policy falls short of providing the space to make that shift. In fact, the policy has been critiqued for failing to provide concrete guidelines regarding what type of participation will be utilized to incorporate communities into the conservation process (Sosovele et al., 1999). The policy is silent on how to best utilize and/or modify existing $\mathrm{CBC}$ and legal structures to achieve the active participation it claims to strive for. Rather, both participation and community are shrouded in ambiguity, raising questions about the operationalization of any 'new' participatory community-based conservation.

\section{REFERENCES}

Adams, W. and D. Hulme (2001) 'Conservation and Community: Changing Narratives, Policies and Practices in African Conservation', in D. Hulme and M. Murphree (eds) African Wildlife and Livelihoods: The Promise and Performance of Community Conservation, pp. 9-23. Portsmouth, NH: Heinemann.

Agrawal, A. (1995) 'Dismantling the Divide between Indigenous and Scientific Knowledge', Development and Change 26(3): 413-39.

Agrawal, A. (1997) 'Community in Conservation: Beyond Enchantment and Disenchantment'. Gainsville, FL: Conservation and Development Forum.

Agrawal, A. and J. Ribot (1999) 'Accountability in Decentralization: A Framework with South Asian and West African Cases', The Journal of Developing Areas 33: 473-562. 
Arhem, K. (1985) Pastoral Man in the Garden of Eden: The Maasai of the Ngorongoro Conservation Area, Tanzania. Uppsala Research Reports in Cultural Anthropology. Uppsala: University of Uppsala.

AWF (African Wildlife Foundation) (n.d.a) 'USAID Support to Partnership Options for Resources Use Innovations (PORI) Project'. Tanzania: African Wildlife Foundation of Tanzania

AWF (n.d.b). 'Partnership Options for Resource Use Innovations Project'. Semi-Annual Report. Tanzania: African Wildlife Foundation of Tanzania

Barrow, E. H. and M. Murphree (2001) 'Community Conservation: From Concept to Practice', in D. Hulme and M. Murphree (eds) African Wildlife and Livelihoods: The Promise and Performance of Community Conservation, pp. 24-37. Portsmouth, NH: Heinemann.

Barrow, E. H., H. Gichohi and M. Infield (2000) Rhetoric or Reality? A Review of Community Conservation Policy and Practice in East Africa. Evaluating Eden Series, No 5. London: International Institute for Environment and Development.

Behnke, R. H., I. Scoones and C. Kerven (eds) (1993) Range Ecology at Disequilibrium: New Models of Natural Variability and Pastoral Adaptation in African Savannas. London: Overseas Development Institute.

Berger, D. (1993) Wildlife Extension: Participatory Conservation by the Maasai of Kenya. Nairobi: Africa Centre for Technology Studies.

Bergin, P. (1995) 'Conservation and Development: The Institutionalization of Community Conservation in Tanzania National Parks'. PhD thesis, University of East Anglia, Norwich.

Bergin, P. (2001) 'Accommodating New Narratives in a Conservation Bureaucracy: TANAPA and Community Conservation', in D. Hulme and M. Murphree (eds) African Wildlife and Livelihoods: The Promise and Performance of Community Conservation, pp. 88-105. Portsmouth, NH: Heinemann.

Berkes, F., J. Colding and C. Folke (2000) 'Rediscovery of Traditional Ecological Knowledge as Adaptive Management', Ecological Applications 10(5): 1251-62.

Bonner, R. (1993) At the Hand of Man: Peril and Hope for Africa's Wildlife. New York: Alfred A. Knopf Inc.

Braun, B. and N. Castree (eds) (1998) Remaking Reality: Nature at the Millennium. London: Routledge.

Brockington, D. (2001) 'Women's Income and Livelihood Strategies of Dispossessed Pastoralists. The Case of Mkomazi Game Reserve', Human Ecology 29: 307-38.

Brockington, D. and K. Homewood (1999) 'Pastoralism around Mkomazi Game Reserve: The Interaction of Conservation and Development', in M. Coe, N. McWilliam, G. Stone and M. Packer (eds) Mkomazi: The Ecology, Biodiversity, and Conservation of a Tanzanian Savanna. London: Royal Geographical Society (with the Institute of British Geographers).

Brush, S. B. and D. Stabinsky (1996) Valuing Local Knowledge: Indigenous People and Intellectual Property Rights. Washington, DC: Island Press.

Collet, D. (1987) 'Pastoralists and Wildlife: Image and Reality in Kenya Maasailand', in D. Anderson and R. Grove (eds) Conservation in Africa, pp. 129-48. Cambridge: Cambridge University Press.

Cronon, W. (ed.) (1996) Uncommon Ground: Towards Reinventing Nature. New York: W. W. Norton \& Co.

Coughenour, M. B. (1991) 'Spatial Components of Plant-Herbivore Interactions in Pastoral, Ranching, and Native Ungulate Ecosystems', Journal of Range Management 44(6): 530-42.

Deihl, C. (1985) 'Wildlife and the Maasai: The Story of East African Parks', Cultural Survival Quarterly 9(1): 37-40.

Fairhead, J. and M. Leach (1996) Misreading the African Landscape: Society and Ecology in a Forest-Savanna Mosaic. Cambridge: Cambridge University Press.

Ferguson, J. (1994) The Anti-Politics Machine: 'Development', Depoliticization and Bureaucratic Power in Lesotho. Minneapolis, MN: University of Minnesota Press. 
Galaty, J. G. (1992) “The Land Is Yours”: Social and Economic Factors in the Privatization, Sub-Division and Sale of Maasai Ranches', Nomadic Peoples 30: 26-40.

Goldman, M. (1998) 'Wildlife Conservation and Pastoral Development in the Semi-Arid Savanna Lands of Tanzania: Changing Views on the Role of Maasai Pastoralists'. Unpublished Masters thesis, University of California, Los Angeles.

Goldman, M. (2002) 'The Relevance of Maasai Place Names for Wildlife Conservation Research in the Tarangire-Manyara Ecosystem, Tanzania'. Third TAWIRI Annual Scientific Conference. Arusha: The Impala Hotel: (3-5 December).

Haraway, D. (1989) Primate Visions: Gender, Race and Nature in the World of Modern Science. New York: Rutledge Press.

Hobart, M. (1993) An Anthropological Critique of Development: The Growth of Ignorance. London: Routledge.

Hodgson, D. (2001) Once Intrepid Warriors: Gender, Ethnicity, and the Cultural Politics of Maasai Development. Bloomington, IN: Indiana University Press.

Hodgson, D. and R. A. Schroeder (2002) 'Dilemmas of Counter-Mapping Community Resources in Tanzania', Development and Change 33(1): 79-100.

Homewood, K. and W. Rodgers (1991) Maasailand Ecology: Pastoralist Development and Wildlife Conservation in Ngorongoro, Tanzania. New York: Cambridge University Press.

Hopkins, B. (1983) 'Successional Processes', in F. Bourliere (ed.) Tropical Savannas: Ecosystems of the World, 13, pp. 605-16. New York: Elsevier Scientific Publishing Company.

Hulme, D. and M. Murphree (1999) 'Communities, Wildlife, and the "New Conservation" in Africa', Journal of International Development 11: 277-85.

Hulme, D. and M. Murphree (eds) (2001) African Wildlife and Livelihoods: The Promise and Performance of Community Conservation. Portsmouth, NH: Heinemann.

Igoe, J. (2001) 'National Parks and Human Ecosystems: The Challenge to Community Conservation A Case-Study from Simanjiro, Tanzania', in D. Chatty and M. Colchester (eds) Conservation and Mobile Indigenous People: Displacement, Forced Settlement, and Conservation, pp. 77-96. Oxford: Berghan Books.

Igoe, J. and D. Brockington (1999) 'Pastoral Land Tenure and Community Conservation: A Case Study from North-East Tanzania'. Pastoral Land Tenure Series, No 11. London: International Institute for Environment and Development.

Jacobs, A. H. (1975) 'Maasai Pastoralism in Historical Perspective', in T. Monad (ed.) Pastoralism in East Africa, pp. 406-22. London: Oxford University Press.

Kahurananga, J. and F. Silkiluwasha (1997) 'The Migration of Zebra and Wildebeest Between Tarangire National Park and Simanjiro Plains, Northern Tanzania, in 1972 and Recent Trends', African Journal of Ecology 35: 179-285.

Kipury, N. (1983) Oral Literature of the Maasai. Nairobi: Heinemann Educational Books.

Kiss, A. (ed.) (1990) Living with Wildlife: Wildlife Resource Management with Local Participation in Africa. Washington, DC: The World Bank.

Kiwasila, H. and K. Homewood (1999) 'Natural Resource Use by Reserve-adjacent Farming Communities', in M. Coe, N. McWilliam, G. Stone and M. Packer (eds) Mkomazi: The Ecology, Biodiversity, and Conservation of a Tanzanian Savanna. London: Royal Geographical Society (with the Institute of British Geographers).

Knowles, J. N. and D. P. Collet (1989) 'Nature as Myth, Symbol and Action: Notes towards a Historical Understanding of Development and Conservation in Kenyan Maasailand', Africa 59: 433-60.

Lama, L. (1998) 'Conflict and Compatibility: An Inventory and Analysis of Land Use in a Tanzanian Wildlife Corridor'. Dissertation, Binghamton University, NY.

Lamprey, H. F. (1964) 'Estimation of the Large Mammal Densities, Biomass and Energy Exchange in the Tarangire Game Reserve and the Masai Steppe in Tanganyika', East African Wildlife Journal 2: 1-46.

Latour, B. (1999) Pandora's Hope: Essays on the Reality of Science Studies. Cambridge, MA: Harvard University Press. 
Leach, M., R. Mearns and I. Scoones (1999) 'Environmental Entitlements: Dynamics and Institutions in Community-Based Natural Resource Management', World Development 27(2): 225-47.

Leader-Williams, N. (2000) 'The Effects of a Century of Policy and Legal Change on Wildlife Conservation and Utilisation in Tanzania', in H. H .T. Prins et al. (eds) Wildlife Conservation by Sustainable Use. Boston, MA: Kluwer Academic Publishers.

LEAT (Lawyers Environmental Action Team) (1998) 'Socio-Legal Analysis of Community Based Conservation in Tanzania: Policy, Legal, Institutional and Programmatic Issues, Considerations and Options'. Report prepared for EPIQ/Tanzanian Natural Resource Management Programme.

Lindsay, W. K. (1987) 'Integrating Parks and Pastoralists: Some Lessons from Amboseli', in D. Anderson and R. Grove (eds) Conservation in Africa. People, Policies and Practice. pp. 149-67. Cambridge: Cambridge University Press.

Little, P. D. (1996) 'Pastoralism, Biodiversity, and the Shaping of Savanna Landscapes in East Africa', Africa 66(1): 37-51.

McCabe, J. T., S. Perkin and C. Schofield (1992) 'Can Conservation and Development be Coupled among Pastoral People? An Examination of the Maasai of the Ngorongoro Conservation Area, Tanzania', Human Organization 51(4): 353-66.

McNaughton, S. J. (1989) 'Ecosystems and Conservation in the Twenty-first Century', in D. Western and M. Pearl (eds) Conservation for the Twenty-first Century, pp. 109-20. New York: Oxford University Press.

McNaughton, S. J. and N. J. Georgiadis (1986) 'Ecology of African Grazing and Browsing Mammals', Annual Review of Ecological Systems 17: 39-65.

McNeely, J. A. (ed.) (1995) Expanding Partnerships in Conservation. Washington, DC: Island Press.

Menaut, J.-C. (1983) 'The Vegetation of African Savannas', in F. Bourliere (ed.) Tropical Savannas: Ecosystems of the World, 13, pp. 109-50. New York: Elsevier Scienctific Publishing Company.

Minja, M. M. J. (1999) 'The Maasai Wonder Plants'. Paper presented at the 'People and Plants' training workshop held at the Tropical Pesticides Research Institute, Arusha, Tanzania (15-18 March).

Muir, A. (1994) 'A Situational Analysis of Pastoralism in Simanjiro District, Tanzania'. Midlothian, Scotland: VETAID.

Mwalyosi, R. B. B. (1991) 'Ecological Evaluation for Wildlife Corridors and Buffer Zones for Lake Manyara National Park, Tanzania, and its Immediate Environment', Biological Conservation 57: 171-86.

Naughton-Treves, L. (1999) 'Whose Animals? A History of Property Rights to Wildlife in Toro, Western Uganda', Land Degradation and Development 10: 311-28.

Neumann, R. P. (1995) 'Local Challenges to Global Agendas: Conservation, Economic Liberalization and the Pastoralists' Rights Movement in Tanzania', Antipode 27(4): 363-82.

Neumann, R. P. (1997) 'Primitive Ideas: Protected Area Buffer Zones and the Politics of Land in Africa', Development and Change 28(4): 559-82.

Niamir-Fuller, M. (1999) Managing Mobility in African Rangelands: The Legitimization of Transhumance. Rome: FAO.

Njoroge, F. W. (2000) 'Report of the Action Learning Training Workshops Held for the Villages of: Lokisalie, Narokauwo, Loborsiret, and Selela'. A Programme for Inyuat e Maa, in collaboration with African Wildlife Foundation.

Ole-Lengisugi, N. (1994) A Survey of MAA Identity and Ancient Ethnoveterinary Animal Husbandry Practices Among the Maasai Pastoralists of Olkoneral: Arusha Region. Working Paper Series, No 3. Nairobi: The African Pastoral Forum.

Ole-Lengisugi, N. and W. R. Mziray (1996) 'The Role of Indigenous Knowledge in Sustainable Ecology and Ethnobotanical Practices Among Pastoral Maasai: Olkonerei-Simanjiro Experience'. Paper presented at the 5th International Congress of Ethnobiology, Tanzania (September). 
O’Malley, M. E. (2000) 'Cattle and Cultivation: Changing Land Use and Labor Patterns in Pastoral Maasai Livelihoods, Loliondo Division, Ngorongoro District, Tanzania'. PhD dissertation. University of Colorado, Boulder.

Parkipuny, M. Ole (1989) 'Pastoralism, Conservation and Development in the Greater Serengeti Region'. Occasional Paper No 1. (City?): The Ngorongoro Conservation and Development Project (NCOP).

Parkipuny, M. Ole (1991) 'The Maasai of East Africa: A People Under the Stranglehold of Preservation'. Paper presented at 'Ethnicity, Equity, and Environment: Confronting a Global Dilemma'. A Stanford Centennial Symposium. Stanford Alumni Association.

Parkipuny, M. Ole and D. Berger (1993) 'Maasai Rangelands: Links Between Social Justice and Wildlife Conservation', in D. Lewis and N. Carter (eds) Voices From Africa: Local Perspectives on Conservation, pp. 113-132. Washington, DC.: WWF.

Peluso, N. L. (1993) 'Coercing Conservation? The Politics of State Resource Control', Global Environmental Change 3: 199-217.

Pimbert, M. P. and J. N. Petty (1995) Parks, People and Professionals: Putting "Participation" into Protected Area Management. Geneva: United Nations Research Institute for Social Development.

Polanyi, M. (1969) 'The Logic of Tacit Inference' (1964). in Marjorie Grene (ed.) Knowing and Being: Essays by M. Polanyi, pp. 138-57. Chicago, IL: University of Chicago Press.

Potkanski, T. (1994) 'Property Concepts, Herding Patterns and Management of Natural Resources among the Ngorongoro and Salei Maasai of Tanzania'. Pastoral Land Tenure Series, No 6, Drylands Programme. London: International Institute for Environment and Development.

Prins, H. H. T. (1987) 'Nature Conservation as an Integral Part of Optimal Land Use in East Africa: The Case of the Masai Ecosystem of Northern Tanzania', Biological Conservation 40: $141-61$.

Ribot, J. C. (1995) 'From Exclusion to Participation: Turning Senegal's Forestry Policy Around?', World Development 23(9): 1587-99.

Ribot, J. C. (1999) 'Decentralization, Participation and Accountability in Sahelian Forestry: Legal Instruments of Political-Administrative Control', Africa 69(1): 23-65.

Rigby, P. (1992) Cattle, Capitalsim and Class: Ilparakuyo Maasai Transformations. Philadelphia, PA: Temple University Press.

Rogers, P. J., D. Brockington, H. Kiwasila and K. Homewood (1999) 'Environmental Awareness and Conflict Genesis: People versus Parks in Mkomazi Game Reserve', in T. Granfelt (ed.) Managing the Globalised Environment, pp. 26-51. London: Intermediate Technology Publications.

Schonewald-Cox, C. M. and J. W. Bayless (1986) 'The Boundary Model: A Geographical Analysis of Design and Conservation of Nature Reserves', Biological Conservation 38: 305-22.

Scoones, I. (ed) (1995) Living With Uncertainty: New Directions in Pastoral Development in Africa. London: International Institute for Environment and Development (IIED).

Scott, J. (1998) Seeing Like A State. New Haven, CT: Yale University Press.

Sekamaganga, L. (n.d.) 'Community Based Conservation Training Institute, Syllabus'. Tanzania, Ministry of Natural Resources and Tourism: Wildlife Division.

Severre, E. L. M. (2000) 'Conservation of Wildlife outside Core Wildlife Protected Areas in the New Millennium'. Speech presented at a conference organized by the College of African Wildlife Management, Mweka, Tanzania (13-15 December).

Shivji, I. G. (1996a) 'Grounding the Debate on Land: The National Land Policy and its Implications', in Debating Land: Proceedings of the Workshop on the National Land Policy, 3rd April 1996. Dar es Salaam: LARRRI/HAKIARDHI (mimeo).

Shivji, I. G. (1996b) 'Contradictory Perspectives on Rights and Justice in the Context of Land Tenure Reform in Tanzania'. Dar es Salaam: LARRRI/HAKIARDHI (mimeo). 
Someshwar, S. (1993) 'People versus the State? Social Forestry in Kolar, India', in J. Friedmann and H. Rangan (eds) In Defense of Livelihood, pp. 182-208. Geneva: United Nations Research Institute for Social Development.

Sosovele, H., F. Shechambo and G. Jambiya (1999) 'Roundtable Discussion on Wildlife Policy (1998) and Community Based Conservation. IRA and EPIQ-TZ'. Tanzania: Bagamoyo (25-26 January).

Taylor, G. and L. Johansson (1996). 'Our Voices, Our Words and Our Pictures: Plans, Truths and Videotapes in Ngorongoro Conservation Area', Forest Trees and People Newsletter (March).

TMCP (Tarangire-Manyara Conservation Project) (2002) Final Report. Istituto Oikos and University of Insubria (Italy) in Collaboration with TANAPA. Project funded by USAID through WWF/TTP. Tanzania: WWF and AWF.

Turner, M. D. (1998) 'The Interaction of Grazing History with Rainfall and Its Influence on Annual Rangeland Dynamics in the Sahel', in K. Zimmerer and K. Young (eds) Nature's Geography: New Lessons for Conservation in Developing Countries. Madison, WI: University of Wisconsin Press.

Turner, M. D. (1999a) 'Merging Local and Regional Analyses of Land-Use Change: The Case of Livestock in the Sahel', Annals of the Association of American Geographers 89(2): 191-219.

Turner, M. D. (1999b) 'The Role of Social Networks, Indefinite Boundaries and Political Bargaining in the Ecological and Economic Resiliency of the Transhumance Systems of Sudano-Sahelian West Africa', in M. Niamir-Fuller (ed.) Managing Mobility in African Rangelands: The Legitimization of Transhumance, pp. 97-123. London: Intermediate Technology Publications.

URT (The United Republic of Tanzania), Ministry of Natural Resources and Tourism (1998) The Wildife Policy of Tanzania. Dar es Salaam: Government Printer.

URT (2000) 'DRAFT - Wildlife Management Area (WMA) Guidelines'. Dar es Salaam: Ministry of Natural Resources and Tourism, Wildlife Division.

Voeten, M. M. (1999) 'The Potential for Competition Between Wild Herbivores and Livestock in the Masai Ecosystem'. Dissertation, Wageningen University.

Voeten, M. M. and H. H. Prins (1999) 'Resource Partitioning between Sympatric Wild and Domestic Herbivores in the Tarangire Region of Tanzania', Oecologia 120(2): 287-94.

Voeten, M. M., C. A. D. M. van de Vijver and H. Olff (n.d.) 'Effects of Grazing on Forage Quality and Forage Quantity for Migratory Ungulates in the Masai Ecosystem, Northern Tanzania'. (Unpublished ms).

Walker, B. H. (1993) 'Rangeland Ecology: Understanding and Managing Change', Ambio 22(2-3): 80-87.

Western, D. (1989) 'Conservation Without Parks: Wildlife in the Rural Landscape', in D. Western and M. Pearl (eds) Conservation for the Twenty-first Century, pp. 158-67. New York: Oxford University Press.

Western, D. and H. Gichohi (1993) 'Segregation Effects and the Impoverishment of Savanna Parks: The Case for Ecosystem Viability Analysis', African Journal of Ecology 31: 269-81.

Western, D. and M. Wright (eds) (1994) Natural Connections: Perspectives in Community-based Conservation. Washington, DC: Island Press.

Wildlife Division (1999) Proceedings of a Workshop on the Formulation of Wildife Management Areas (WMAs) Guidelines. Arusha: Impala Hotel (15-19 December). Dar es Salaam: Ministry of Natural Resources and Tourism, Wildlife Division.

Zimmerer, K. S. (2000) 'The Reworking of Conservation Geographies: Nonequilibrium Landscapes and Nature-Society Hybrids', Annals of the Association of American Geographers 90(2): 356-69. 
Mara Goldman is a PhD student in the Department of Geography at the University of Wisconsin-Madison. She is currently in Tanzania conducting her main dissertation fieldwork (January 2002 to January 2004), which builds on many of the ideas expressed in this article. Her research interests include the political ecology of environmental resource management, the politics of participation, the politics of knowledge (indigenous and scientific), pastoral management regimes, and ecology of semi-arid ecosystems. 